\title{
Pseudopseudohypoparathyroidism With a Novel Mutation in the GNAS Gene Showing Thin Bones of Extremities and Ossification of Entheses
}

\author{
Hidetaka Hamasaki ${ }^{\mathrm{a}}$, Takahiko Mukaino ${ }^{\mathrm{b}}$, Hiroshi Kaneko ${ }^{\mathrm{c}}$, Toshikatsu Mitsui ${ }^{\mathrm{d}}$, \\ Sumie Moriyama ${ }^{a}$, Tomonobu Hasegawa ${ }^{\mathrm{d}}$, Hidekatsu Yanai ${ }^{\mathrm{a}, \mathrm{e}}$
}

\begin{abstract}
Pseudopseudohypoparathyroidism (PPHP) is an extremely rare disorder caused by mutations in the GNAS gene. PPHP as well as pseudohypoparathyroidism (PHP) shows Albright hereditary osteodystrophy (AHO) such as mental retardation, round face, short stature, central obesity, short fingers and toes. Here we report a patient with PPHP and type 2 diabetes who had a novel mutation in the GNAS gene and showed atypical heterotopic ossification, ossification of entheses, and also thin bones of extremities, in addition to characteristic clinical features for AHO.
\end{abstract}

Keywords: Albright hereditary osteodystrophy; Ossification of entheses; Pseudopseudohypoparathyroidism; Thin bones; Type 2 diabetes

\section{Introduction}

Pseudopseudohypoparathyroidism (PPHP) is an extremely rare disorder caused by mutations in the GNAS gene [1] Mutations in GNAS, the imprinted gene complex encoding the $\alpha$-subunit of the stimulatory G protein (Gas) are responsible for some inherited disorders such as pseudohypoparathyroidism (PHP) and PPHP [2]. These disorders usually show heterotopic ossification as a clinical feature of Albright

\footnotetext{
Manuscript accepted for publication November 28, 2013

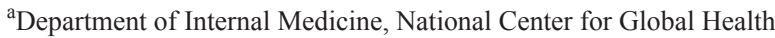
and Medicine Kohnodai Hospital, Chiba, Japan

${ }^{\mathrm{b}}$ Department of Neurology, Kyushu University, Fukuoka, Japan

${ }^{\mathrm{c}}$ Department of Rheumatology, National Center for Global Health and

Medicine Kohnodai Hospital, Chiba, Japan

${ }^{\mathrm{d}}$ Department of Pediatrics, Keio University School of Medicine, Tokyo, Japan

${ }^{\mathrm{e} C}$ Corresponding author: Hidekatsu Yanai, Department of Internal

Medicine, National Center for Global Health and Medicine Kohnodai

Hospital, 1-7-1 Kohnodai, Chiba 272-8516, Japan.

Email: dyanai@hospk.ncgm.go.jp

doi: http://dx.doi.org/10.4021/jem198w
}

hereditary osteodystrophy (AHO) [3]. However, GNAS-associated disorders of heterotopic ossification have a broad clinical spectrum $[4,5]$, and its phenotype has not been fully understood. Progressive osseous heteroplasia (POH), another disorder of ectopic extraskeletal ossification, is dermal and subcutaneous ossification. The bone formation is more severe and ossification progresses into muscle and deep connective tissue during childhood [6]. To date, some cases with features of both $\mathrm{AHO}$ and $\mathrm{POH}-$ like heterotopic ossification have been described [7]. In this report, we describe a patient with PPHP and type 2 diabetes with a novel mutation in the GNAS gene that shows atypical heterotopic ossification and thin bones of extremities.

\section{Case Report}

A 46-year-old woman was admitted for the treatment of type 2 diabetes. She was diagnosed as having type 2 diabetes 2 years ago. She had mental retardation and epileptic seizure in early childhood. Her gait was unstable until she became 6 years old. Her father, paternal grandmother and aunt also had mental retardation. Her body height, weight, body mass index and abdominal circumference were $149.5 \mathrm{~cm}, 76.2 \mathrm{~kg}$, $34.2 \mathrm{~kg} / \mathrm{m} 2$ and $92 \mathrm{~cm}$, respectively. She showed round face, short stature, central obesity and short fingers and toes, suggesting the existence of AHO. She also has pleasant nature, supporting the diagnosis of AHO. Surprisingly, her bones of extremities were very thin (Fig. 1), with normal bone density. Normal serum levels of calcium, inorganic phosphorus and intact parathyroid hormone (PTH), and a negativity of the Ellsworth-Howard test suggested the existence of PPHP. Interestingly, ossification of entheses was also observed (Fig. 2). DNA sequence analysis showed a novel mutation in exon 1 (c.137 T > G, L46P) of the GNAS gene (Fig. 3). She was heterozygous for this mutation.

\section{Discussion}

PPHP is caused by mutations in the GNAS gene and is inherited in an autosomal dominant fashion. When inherited 

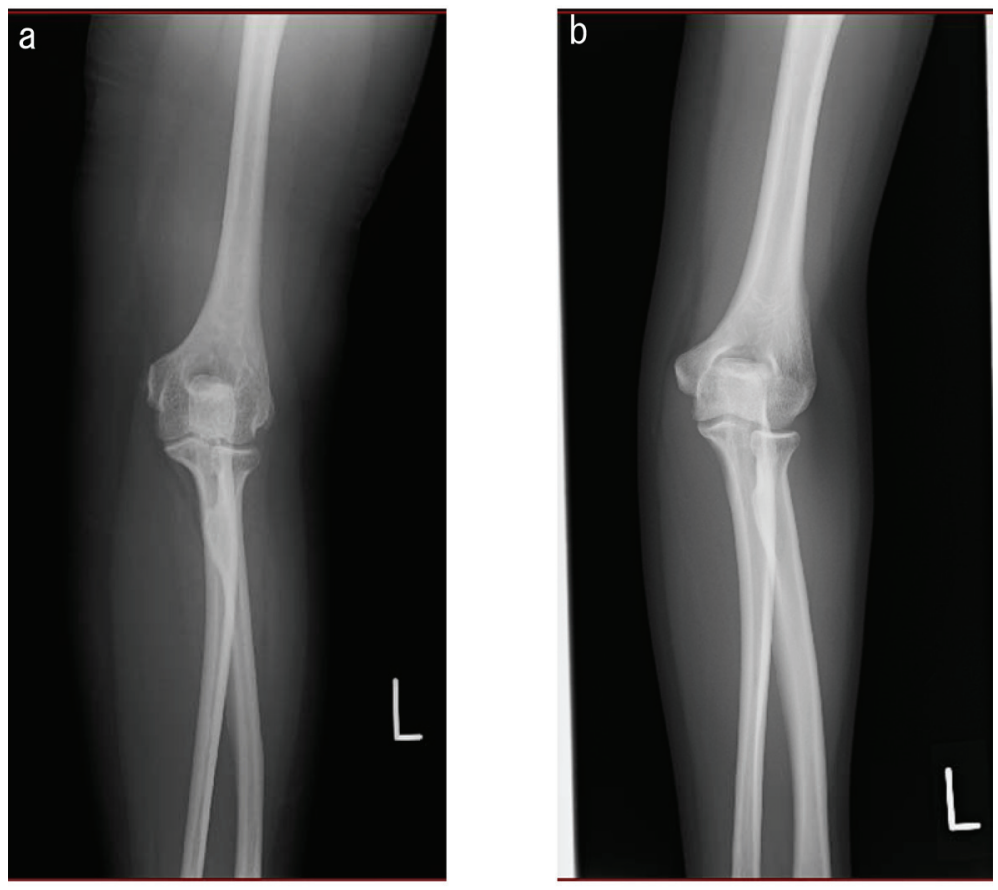

Figure 1. Radiograph of arm in a patient with pseudopseudohypoparathyroidism. Arm of (a) a patient and (b) a 35-year-old normal woman with body height $154 \mathrm{~cm}$, body weight $46 \mathrm{~kg}$ and body mass index 19.4 $\mathrm{kg} / \mathrm{m}^{2}$.

paternally, heterozygous GNAS mutations affecting GNAS exons that encode Gas, cause PPHP characterized by the clinical features including round face, short stature, central obesity, subcutaneous ossifications and short fingers and toes

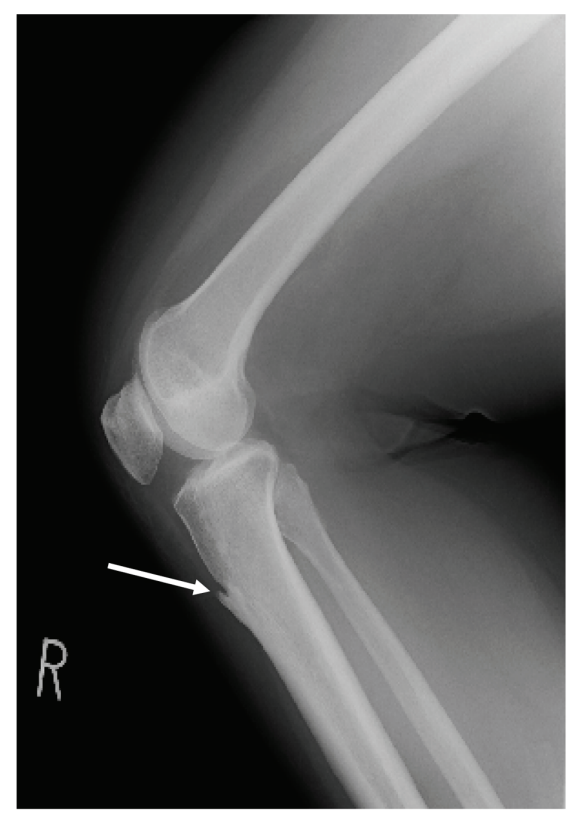

Figure 2. Radiograph of knee in a patient with pseudopseudohypoparathyroidism. Arrow indicates ossification of entheses. observed in $\mathrm{AHO}$ in the absence of hormones resistance [3]. When inherited maternally, heterozygous mutations cause PHP type Ia (PHP Ia) [8]. Our patient was heterozygous for a novel mutation of the GNAS gene. It is exactly unknown whether her father had the same mutation of the GNAS gene, because her father already died. Her father also had mental retardation and clinical features similar to our patient, suggesting that her GNAS gene mutation might be possibly inherited paternally. PPHP is a genomic imprinting disorder resulting from decreased activity of GNAS, and is usually inherited from the father [2]. GNAS is a complex imprinted gene locus that encodes the signaling protein Gas which couples receptors for hormones and neurotransmitters to activation of adenylyl cyclase [9].

Pure $\mathrm{POH}$ (no other AHO features) is also caused by a paternal inheritance of GNAS mutations [10]. Ossification of entheses as observed in our patient may be a partial clinical presentation of $\mathrm{POH}$ due to a mutation in exon 1 (c.137 T > G, L46P) of the GNAS gene. Our patient also showed thin bones of extremities; however, it remains unknown whether the GNAS mutation influenced bone thinness of extremities or not.

A precise prevalence of PPHP has not ever been reported because PPHP is an extremely rare disease. Furthermore, PPHP complicated with type 2 diabetes is also quite rare [11]. The genetic association between PPHP and type 2 diabetes is also unidentified. To our knowledge, this patient is the first case with PPHP to show thin bones of extremities, 
Exon 1 c.137 T>G (p.L46P)

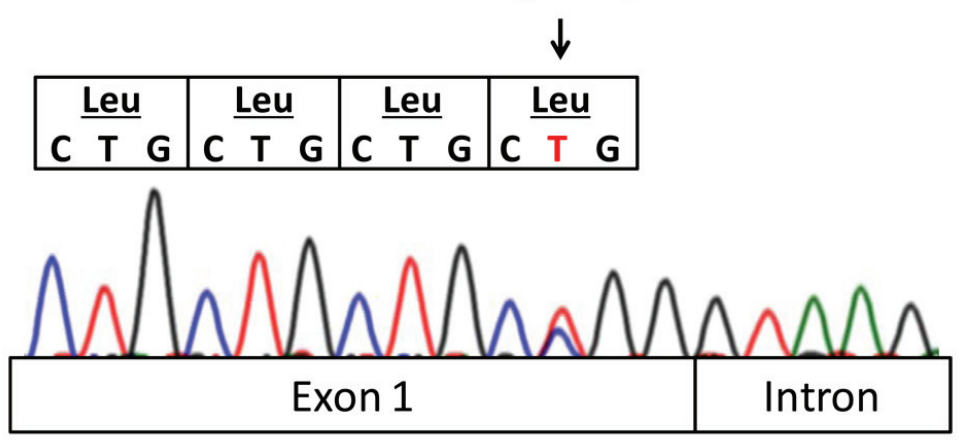

Figure 3. A novel mutation of the GNAS gene in a patient with pseudopseudohypoparathyroidism.

ossification of entheses, in addition to characteristic clinical features for AHO. We should investigate more cases to elucidate the pathophysiology of PPHP.

\section{Acknowledgement}

This work was supported by a grant from the National Center for Global Health and Medicine (25-203).

\section{Conflict Interests}

The authors declare that they have no competing interests.

\section{Funding}

This work was funded by a grant from the National Center for Global Health and Medicine (25-203).

\section{References}

1. Mantovani G. Clinical review: Pseudohypoparathyroidism: diagnosis and treatment. J Clin Endocrinol Metab. 2011;96(10):3020-3030.

2. Weinstein LS, Yu S, Warner DR, Liu J. Endocrine manifestations of stimulatory $\mathrm{G}$ protein alpha-subunit mutations and the role of genomic imprinting. Endocr Rev. 2001;22(5):675-705.

3. Albright F, Forbes AP, Henneman PH. Pseudo-pseudohypoparathyroidism. Trans Assoc Am Physicians.
1952;65:337-350.

4. Adegbite NS, Xu M, Kaplan FS, Shore EM, Pignolo RJ. Diagnostic and mutational spectrum of progressive osseous heteroplasia (POH) and other forms of GNASbased heterotopic ossification. Am J Med Genet A. 2008;146A(14):1788-1796.

5. Schimmel RJ, Pasmans SG, Xu M, Stadhouders-Keet SA, Shore EM, Kaplan FS, Wulffraat NM. GNAS-associated disorders of cutaneous ossification: two different clinical presentations. Bone. 2010;46(3):868-872.

6. Kaplan FS, Craver R, MacEwen GD, Gannon FH, Finkel G, Hahn G, Tabas J, et al. Progressive osseous heteroplasia: a distinct developmental disorder of heterotopic ossification. Two new case reports and follow-up of three previously reported cases. J Bone Joint Surg Am. 1994;76(3):425-436.

7. Eddy MC, Jan De Beur SM, Yandow SM, McAlister WH, Shore EM, Kaplan FS, Whyte MP, et al. Deficiency of the alpha-subunit of the stimulatory $G$ protein and severe extraskeletal ossification. J Bone Miner Res. 2000;15(11):2074-2083.

8. Levine MA. An update on the clinical and molecular characteristics of pseudohypoparathyroidism. Curr Opin Endocrinol Diabetes Obes. 2012;19(6):443-451.

9. Bastepe M, Juppner H. GNAS locus and pseudohypoparathyroidism. Horm Res. 2005;63(2):65-74.

10. Shore EM, Ahn J, Jan de Beur S, Li M, Xu M, Gardner RJ, Zasloff MA, et al. Paternally inherited inactivating mutations of the GNAS1 gene in progressive osseous heteroplasia. N Engl J Med. 2002;346(2):99-106.

11. Wu CJ, Sheu WH. Type 2 diabetes in adults with pseudopseudohypoparathyroidism. Case report. Diabetes Care. 1998;21(9):1575-1576. 